\title{
Oxidatively Modified LDL Contains Phospholipids With Platelet-activating Factor-like Activity and Stimulates the Growth of Smooth Muscle Cells
}

James M. Heery, Mark Kozak, Diana M. Stafforini, David A. Jones, Guy A. Zimmerman, Thomas M. McIntyre, and Stephen M. Prescott

The Nora Eccles Harrison Cardiovascular Research \& Training Institute, the Eccles Program in Human Molecular Biology \& Genetics, and the Departments of Internal Medicine and Biochemistry, The University of Utah, Salt Lake City, Utah 84112

\begin{abstract}
Oxidative modification of lipoproteins is believed to be important in the genesis of atherosclerosis. We established cultures of smooth muscle cells (SMC) and exposed them to native LDL or oxidized LDL. Oxidized LDL, but not native LDL, was mitogenic as measured by incorporation of $\left[{ }^{3} \mathrm{H}\right]$ thymidine into DNA. This effect was concentration dependent, averaged $288 \%$ of control, and was blocked by a platelet-activating factor (PAF) receptor antagonist. We hypothesized that phospholipids with PAF-like activity were generated during the oxidation of LDL. To test this hypothesis we extracted phospholipids from copper-oxidized LDL and assayed for PAF-like activity. Phospholipids extracted from oxidized LDL and purified by HPLC induced neutrophil adhesion equivalent to PAF (10 $\mathrm{nM}$ ) and were mitogenic for smooth muscle cells. These effects were not seen with phospholipids extracted from native LDL and were blocked by two structurally different, competitive antagonists of the PAF receptor. The effects of these lipids were also abolished by pretreating them with PAF acetylhydrolase. Finally, we used Chinese hamster ovary cells that had seen stably transfected with a cDNA for the PAF receptor to confirm that phospholipids from oxidized LDL act via this receptor. We found that PAF (control) and the oxidized phospholipids each induced release of arachidonic acid from the transfected cells, but had no effect on wildtype Chinese hamster ovary cells, which lack the PAF receptor. This effect was also blocked by a PAF receptor antagonist. Thus, phospholipids generated during oxidative modification of LDL may participate in atherosclerosis by stimulating SMC proliferation and leukocyte activation. ( $J$. Clin. Invest. 1995.96:2322-2330.) Key words: phospholipids - platelet-activating factor • smooth muscle • atherosclerosis - inflammation
\end{abstract}

\section{Introduction}

Increased levels of LDL are strongly associated with an increased risk of atherosclerosis (1-3). The mechanisms by

Address correspondence to Stephen M. Prescott, Eccles Institute of Human Genetics, Building 533, Room 4220, University of Utah, Salt Lake City, UT 84112. Phone: 801-585-3401; FAX: 801-585-6345.

Received for publication 28 February 1994 and accepted in revised form 19 July 1995.

J. Clin. Invest.

(C) The American Society for Clinical Investigation, Inc

0021-9738/95/11/2322/09 \$2.00

Volume 96, November 1995, 2322-2330 which elevated levels of LDL lead to atherosclerosis are not fully elucidated. However, there is evidence that LDL must be modified to become pathogenic (4-6). Modification of LDL may be accomplished in vitro by a variety of chemical methods, including oxidation, or by incubation with one of the cell types found in the vascular wall (endothelial cells, macrophages, or smooth muscle cells) $(7,8)$. Several experimental findings indicate that the cell-mediated modification of LDL is due to the generation of oxidants by the cells $(8,9)$. This is an attractive hypothesis as it could explain how LDL modification occurs in vivo and is supported by studies in animals that have shown a protective effect of antioxidants against atherosclerosis (1013). Regardless of the mechanisms of LDL modification, once it has occurred the LDL particle (specifically the apolipoprotein B-100) is no longer recognized by the LDL receptor (14). Instead, the modified LDL is recognized by a scavenger receptor which is abundant on endothelial cells (ECs) and macrophages $(15,16)$. This change is significant in that the LDL receptor is downregulated in response to LDL uptake by a negative feedback mechanism, whereas the scavenger receptor is not under negative feedback control. This allows large amounts of cholesterol from modified LDL to accumulate in cells via this receptor. Unregulated uptake of modified LDL by macrophages leads to their transformation into foam cells, which are components of the first histologically visible lesion of atherosclerosis - the fatty streak.

In addition to the deposition of cholesterol, atherosclerotic lesions are characterized by the proliferation of smooth muscle cells (SMC) ${ }^{1}$ and by the infiltration of monocytes and macrophages. Modified LDL may affect these cellular processes as well. It is known that modified LDL is toxic to endothelial cells, attracts monocytes, and inhibits the mobility of macrophages (6). The recruitment of monocytes to the vascular wall may also involve indirect mechanisms. For example, LDL that has been minimally modified induces transcription and translation of the gene for monocyte chemotactic protein-1 in smooth muscle cells (17) and induces endothelial cells to produce GmCSF (18). Modified LDL also inhibits endothelium-dependent vasorelaxation and potentiates vasoconstriction (19-21). Several investigators have studied the effects of LDL and modified LDL on smooth muscle cell proliferation. Fless et al. found that human LDL particles were mitogenic for smooth muscle cells cultured from monkey aorta (22). Koschinsky noted a small mitogenic effect of LDL from hypercholesterolemic, but not from normocholesterolemic, human blood donors (23). Others have found that LDL increased the turnover of phosphatidylinositol in rat and human arterial smooth muscle cells implying a

1. Abbreviations used in this paper: BHT, butylated hydroxytoluene DFP, diisopropylfluorophosphate; PAF, platelet-activating factor; SMC, smooth muscle cell. 
stimulatory effect on cellular proliferation $(24,25)$. The latter group also noted an increase in intracellular $\mathrm{pH}$, translocation of protein kinase $\mathrm{C}$ to the cell membrane, and protooncogene expression. Surprisingly, they did not find an increase in incorporation of $\left[{ }^{3} \mathrm{H}\right]$ thymidine. Sachinidis et al. $(26,27)$ found that LDL from normocholesterolemic donors increased intracellular $\mathrm{pH}$ and calcium concentrations in smooth muscle cells from rat aorta. In these experiments $\left[{ }^{3} \mathrm{H}\right]$ thymidine incorporation was increased indicating that cellular proliferation was stimulated. The same group later reported that oxidized LDL caused a greater increase in intracellular calcium that native LDL (28). Finally, Resink et al. found that oxidized LDL increased phosphatidylinositol turnover by a larger amount than did native LDL in smooth muscle cells from human arterioles (29). They concluded that the process was mediated by a receptor that recognized a modified protein, as lipid extracts from native $L D L$ had no effect.

LDL is $\sim 75 \%$ lipid by weight, and the polyunsaturated fatty acids in phospholipids and cholesterol esters may be the initial sites of oxidative attack during modification of the particle. There is evidence that the products of these reactions modify the apolipoprotein $(14,30)$ Further, lyso-phosphatidylcholine (lyso-PC) is produced during LDL oxidation; and monocyte recruitment (31) the inhibition of endothelium-dependent relaxation $(19,20)$ and smooth muscle cell growth $(32,33)$ have been attributed to this compound.

We and others have shown that phospholipid autacoids are important intercellular messengers in both physiologic and pathologic situations (reviewed in reference 34 ). Platelet-activating factor (PAF) activates platelets and leukocytes, and increases vascular permeability among other actions. Initially identified as a mediator of anaphylaxis in rabbits, PAF is now recognized to be synthesized by, and to act upon, many types of cells. For example, Stoll and Spector (35) reported that PAF is a mitogen for vascular SMC and that it is synergistic with PDGF in this effect. PAF was the first phospholipid for which a receptor was identified, and the cDNA for this receptor has now been cloned and expressed in cell lines $(36,37)$. The PAF receptor is specific for choline phosphoglycerides with a short chain fatty acyl residue at the $s n-2$ position. Work in our laboratory has focused on the role of PAF in recruiting neutrophils through its expression on the surface of activated endothelia cells. We have also shown that oxidatively fragmented phospholipids (PAF-like lipids) are recognized by the PAF receptor and have similar bioactivity $(38,39)$. These PAF-like lipids have been produced by exposure of synthetic phosphatidylcholine (PC) to ozonolysis or to lipoxygenase (38), and by exposing cultured cells to oxidants (39). These compounds are inactivated by PAF acetylhydrolases $(40,41)$, a family of enzymes that specifically degrade PAF and related compounds by cleaving the ester bond at the $s n-2$ position. Like the receptor, this enzyme is specific for choline phosphoglycerides that have a short chain fatty acid at the $s n-2$ position (42). Interestingly, the plasma form of PAF acetylhydrolase is associated with lipoproteins, primarily LDL, but also $\operatorname{HDL}(42,43)$. Klimov et al. (44) showed that a coincubation of HDL with LDL inhibited iron-induced oxidation of LDL, and Parthasarathy et al. (45) demonstrated a protective effect of HDL on cell-induced oxidation of LDL. We showed that HDL slows the oxidation of LDL, and that much of the protection depends on the presence of PAF acetylhydrolase (46). Watson and colleagues also found that PAF acetylhydrolase prevented the development of mini- mally modified LDL, implicating a PAF-like lipid in the process (47).

In the studies reported here we tested the hypotheses that oxidatively modified LDL stimulates the growth of smooth muscle cells, and that the oxidation of LDL generates phospholipids with PAF-like activity that may account for this effect.

\section{Methods}

Materials. M-199, penicillin/streptomycin, and L-glutamine were obtained from Whittaker Bioproducts Inc., (Walkersville,MD). Tissue culture dishes were from Falcon Labware (Lincoln Park, NJ). Trypsin/ EDTA was from GIBCO Laboratories (Grand Island, NY). Fetal bovine serum was from Hyclone (Logan, UT). Recombinant human PDGF was obtained from Upstate Biotechnology Inc. (Lake Placid, NY). $\left[{ }^{3} \mathrm{H}\right]$ thymidine $(6.5 \mathrm{Ci} / \mu \mathrm{mol})$, diisopropylfluorophosphate (DFP), fatty acid-free BSA, and the murine monoclonal anti- $\alpha$-smooth muscle actin were from Sigma Chemical Co. (St. Louis, MO). The fluoresceinconjugated caprine anti-murine IgG was from Cappel Laboratories (West Chester, PA). Agarose gel kits were from CIBA-Corning (Palo Alto, CA), and aminopropyl columns were from J.T. Baker, Inc. (Phillipsburg, NJ). The BCA protein assay kit was from Pierce (Rockford, IL). PAF was obtained from Avanti Polar Lipids (Birmingham, AL). Dialysis tubing (M.W.C.O. 6,000-8,000) was from Spectrum Medical Industries, Inc. (Houston, TX)

1-palmitoyl-2-[5-oxovaleroyl]-sn-3-glycerophosphocholine (5-ALPC) was synthesized and purified as previously described (40). PAF acetylhydrolase was purified (42) and used (40) as previously described. WEB 2086 was a gift from Peggy Ganong of Boehringer Ingelheim Pharmaceuticals, Inc. (Ridgefield, CT), and L659,989 was a gift from John Chabala of Merck, Sharp, and Dohme Research (Rahway, $\mathrm{NJ}$ ).

Culture and characterization of smooth muscle cells from bovine coronary arteries. Bovine hearts were obtained from a local abattoir and the coronary arteries were dissected free under sterile conditions. The smooth muscle cells subsequently were isolated by an explant technique. They were grown in M-199 supplemented with $10 \%$ FCS, 100 $\mathrm{U} / \mathrm{ml}$ penicillin, $100 \mu \mathrm{g} / \mathrm{ml}$ streptomycin, and $2 \mu \mathrm{M} \mathrm{L}$-glutamine at $37^{\circ} \mathrm{C}$ in $5 \% \mathrm{CO}_{2}$. When growth was dense, the tissue pieces were removed with forceps, and the cells were passed using trypsin $(0.05 \%)$ in EDTA $(0.53 \mu \mathrm{M})$. The identity of the cultured cells was established by their typical "hill and valley" morphology under phase-contrast microscope, and confirmed by staining with a murine monoclonal antibody to $\alpha$ smooth muscle actin; the second antibody was a fluorescein-labeled, caprine anti-mouse IgG. With this method, the cells showed uniform fibrillar staining. The cells were routinely used in first or second passage and were allowed to grow to confluence before use. The medium was changed every $2-3 \mathrm{~d}$.

Culture of smooth muscle cells from rat aorta. Rat A10 vascular smooth muscle cells were obtained from ATCC (Rockville, MD) and were cultured in 96-well plates in DME containing $15 \%$ FCS at $37^{\circ} \mathrm{C}$ in $5 \% \mathrm{CO}_{2}$. The cells were plated at a density of approximately $10^{4}$ per well and were used when confluent.

Assay of bovine cell growth. $24 \mathrm{~h}$ before the cells were to be used, the serum-containing medium was removed and replaced with serumfree M-199 containing penicillin, streptomycin, L-glutamine, and $1 \mathrm{mg} /$ $\mathrm{ml}$ BSA. The test compound was prepared in the same medium, filtered through a 0.2 micron filter, warmed to $37^{\circ} \mathrm{C}$, and placed on the cells The cells were returned to the incubator. After $20 \mathrm{~h}, 0.5 \mu \mathrm{Ci}$ of $\left[{ }^{3} \mathrm{H}\right]-$ thymidine were added to each well, and the cells were returned to the incubator for four more hours. The cells were harvested by aspiration of the medium, followed by washing with ice-cold methanol. Ice cold $10 \%$ trichloroacetic acid was then added to precipitate proteins and nucleic acids. The residue was solubilized by the addition of $0.3 \mathrm{~N}$ $\mathrm{NaOH} / 1 \%$ sodium dodecylsulfate. A portion was transferred to a scintillation vial, Opti-Fluor (Packard Instrument Co., Meriden, CT) was added, and the radioactivity was measured by scintillation spectrometry. 
BSA-containing medium without additions was used as the control. PDGF at different concentrations, but usually at $1 \mathrm{ng} / \mathrm{ml}$, was used as a positive control. The assays were carried out in triplicate for each condition in each experiment. For lipoprotein-containing solutions, the concentration of BSA was adjusted to keep the total protein concentration constant.

The cells were always examined by inverted phase-contrast microscopy at the initiation and conclusion of each incubation, and we found a qualitatively concordant result with the thymidine incorporation. Additionally, in several control experiments we determined the number of cells before and after stimulation and found an excellent correlation with thymidine incorporation.

Assay of rat A10 cell growth. $18 \mathrm{~h}$ before the cells were to be used the medium was removed and replaced with DME containing $1 \%$ FCS. The test compound was dissolved in PBS containing 0.1\% BSA, warmed to $37^{\circ} \mathrm{C}$, and added to the cells. PDGF at $30 \mathrm{ng} / \mathrm{ml}$ was used as a positive control. The cells were incubated at $37^{\circ} \mathrm{C}$ for $18 \mathrm{~h}$. The medium was then supplemented with $1 \mu \mathrm{Ci}$ of $\left[{ }^{3} \mathrm{H}\right]$ thymidine for $1 \mathrm{~h}$. The medium was removed and ice-cold $25 \%$ trichloroacetic acid was added. Precipitated material was washed three times with $25 \%$ trichloroacetic acid then solubilized in $0.25 \mathrm{~N} \mathrm{NaOH}$. Soluble material was neutralized by addition of $0.25 \mathrm{~N} \mathrm{HCl}$, transferred to scintillation vials, and counted. The assays were carried out in triplicate for each condition in each experiment. The cells were examined by inverted phase-contrast microscopy at the initiation and conclusion of each incubation.

Isolation and modification of $L D L$. Blood was drawn from fasting volunteers into $2.5 \mu \mathrm{M}$ EDTA. In some experiments $200 \mu \mathrm{M}$ butylated hydroxytoluene (BHT) was included in the syringe to provide continuous protection against oxidation. The plasma was separated by centrifugation at $800 \mathrm{~g}$ for $20 \mathrm{~min}$ at $4^{\circ} \mathrm{C}$. The specific gravity of the plasma was adjusted to 1.3 by the addition of $\mathrm{KBr}$, and the lipoproteins were separated by ultracentrifugation (48). The LDL fractions were isolated by density flotation (s.g. 1.017-1.062), pooled, and dialyzed overnight against PBS ( $\mathrm{pH} \mathrm{7.4)} \mathrm{with} \mathrm{at} \mathrm{least} \mathrm{two} \mathrm{changes} \mathrm{of} \mathrm{dialysate.} \mathrm{After}$ dialysis, the protein concentration was determined with the Pierce BCA kit using BSA as the standard. For some experiments a portion of the LDL was treated with diisopropylfluorophosphate (DFP) as previously described, to inactivate the PAF acetylhydrolase (46). Unreacted DFP was removed by dialysis. In these experiments, control LDL (i.e., not exposed to DFP) was handled in an otherwise identical manner.

In experiments in which we tested the effects of oxidized LDL, we obtained the oxidized form by incubating the isolated LDL $(200 \mu \mathrm{g}$ protein $/ \mathrm{ml})$ with copper sulfate $(10 \mu \mathrm{M})$ for $18 \mathrm{~h}$ at $37^{\circ} \mathrm{C}$. Modification of the apolipoprotein B-100 was assessed by measuring the electrophoretic mobility in an agarose gel using barbital buffer ( $\mathrm{pH} \mathrm{8.6)}$. For experiments in which a portion of the blood had been drawn into BHT, equivalent amounts of this antioxidant were added to the remaining sample after oxidation to exclude a direct effect of BHT on the cells. For use with smooth muscle cells, the oxidized-LDL and native LDL were then dialyzed against M-199 with penicillin/streptomycin and Lglutamine. The LDL was diluted to the appropriate final concentration using the same medium with enough BSA to maintain a final protein concentration of $1 \mathrm{mg} / \mathrm{ml}$.

Analysis of lipids. Total lipids were extracted from LDL by the method of Bligh and Dyer (49). The amount of phospholipid was determined by the microphosphate technique (50). Separation of total lipids into neutral lipids, fatty acids, and phospholipids was done on aminopropyl columns using sequential elution with $67 \%$ chloroform/ $33 \%$ isopropanol, then $1 \%$ acetic acid in diethyl ether, and finally methanol (51). Further purification of the phospholipid fraction was accomplished by reversed-phase HPLC using a $250 \times 4.6 \mathrm{~mm}$ ODS column ( $5 \mu$ Microsorb MV; Rainen Instrument Co., Woford, MA.) and a mobile phase of $84 \%$ methanol $/ 15 \%$ acetonitrile/1\% deionized water containing $1 \mu \mathrm{M}$ ammonium acetate at a flow rate of $1 \mathrm{ml} / \mathrm{min}$. The effluent was collected in $1-\mu l$ fractions. In additional experiments we used another HPLC system with the same column but a gradient mobile phase (system 2) to achieve better separation of the active material. In this procedure we used the same solvent as above as solvent $\mathrm{B}$, while solvent
A was the same composition but with $10 \%$ water. The gradient protocol was a continuous flow rate of $1 \mathrm{ml} / \mathrm{min}$ beginning with $100 \%$ solvent A until $5 \mathrm{~min}$ after injection. At that time we began a linear gradient to $100 \%$ solvent $\mathrm{B}$ at $55 \mathrm{~min}$. In this system, PAF elutes at $13 \mathrm{~min}$, lysophosphatidylcholine at 8-9 $\mathrm{min}$, and phosphatidylcholine at 25-26 min.

Assays for PAF-like bioactivity. We used two assays for quantifying PAF-like bioactivity. In the first, neutrophils were isolated from human blood (52), placed in gelatin-coated wells and then the test compounds were added for a 10-min incubation (53). The nonadherent cells were removed by washing and the number of adherent cells was counted with a video microscopy system that images $20 \%$ of the well. Authentic PAF and FMLP were used as positive controls and buffer alone was the negative control. Adhesion in this assay is dependent on activation of neutrophils with functional upregulation of the $\beta_{2}$-integrin CD11b/ CD18 (38).

In the second assay we used Chinese hamster ovary ( $\mathrm{CHO}$ ) cells that had been stably transfected with the human PAF receptor as a target for PAF-like actions. These cells were a gift from Dr. Patrick Gray (ICOS Corp., Bothell, WA). The cDNA encoding the PAF receptor (in pcDNA/Neo) was transfected into $\mathrm{CHO}$ cells with Lipofectin. Stable transfectants were selected by growth in medium that contained 600 $\mu \mathrm{M}$ G418. To assay responses to PAF and oxidized phospholipids the transfected cells and wild-type $\mathrm{CHO}$ cells (which lack the PAF receptor and do not respond to PAF) were incubated with $\left[{ }^{3} \mathrm{H}\right]$ arachidonic acid $(0.5 \mu \mathrm{Ci} / \mathrm{ml})$ in fatty acid-free BSA for $3 \mathrm{~h}$. The principle of the assay is that the PAF receptor is functionally coupled to phospholipase $\mathrm{A}_{2}$ and causes release of arachidonate in many cell types (34). After labeling, the cells were washed with buffer that contains fatty acid-free bovine serum albumin to remove arachidonic acid that had not been incorporated into cellular lipids. The cells were then stimulated with PAF, test compounds such as oxidized phospholipids, or control medium containing calcium ionophore A23187 (positive) or buffer alone (negative). The supernatant was removed and the amount of $\left[{ }^{3} \mathrm{H}\right]$ arachidonic acid released was determined by scintillation spectrometry. When incubated with PAF the $\mathrm{CHO}$ transfectants released radiolabeled arachidonic acid. This response was dependent on the concentration of PAF, and was blocked by antagonists of the PAF receptor. Wild-type CHO cells did not respond to PAF, nor did $\mathrm{CHO}$ cells transfected with vector alone.

\section{Results}

Some groups have shown that LDL stimulates the growth (or related responses) of smooth muscle cells while others have found no effect $(22,24-27)$. We reexamined the hypothesis that oxidized LDL accounted for the growth-stimulatory actions. In initial studies we found that LDL, which we assumed was in its native state, and LDL that we had purposefully oxidized both stimulated the incorporation of $\left[{ }^{3} \mathrm{H}\right]$ thymidine into smooth muscle cells (not shown). However, when blood was drawn directly into tubes containing an antioxidant (BHT) and a chelator of transition metals (EDTA), and these compounds were kept present during the entire isolation and preparation of LDL, we found that the LDL that had been protected from oxidation did not stimulate smooth muscle cells to incorporate thymidine into DNA $(n=3)$. In these same experiments, we tested the effect of LDL that was prepared from blood that had not had the antioxidant added at the time of collection, and then had been oxidized by exposure to copper sulfate. This oxidized LDL consistently stimulated the growth of smooth muscle cells (Fig. 1). We excluded the possibility that the differences observed in the two forms of LDL was the result of a direct inhibitory effect of BHT on the cells by adding it to the same final concentration in the oxidized LDL preparation after the 


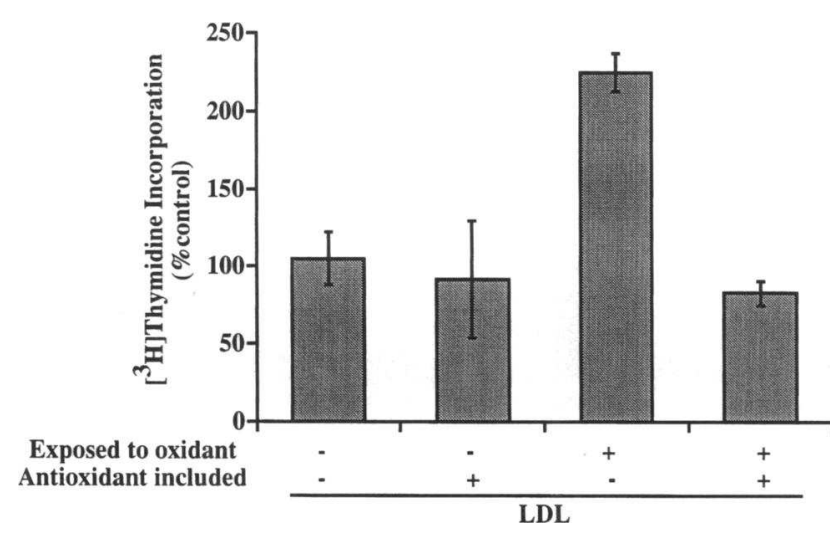

Figure 1. Oxidized LDL stimulates the growth of smooth muscle cells from bovine coronary arteries. Smooth muscle cells cultured from bovine coronary arteries were incubated in serum-free medium for $24 \mathrm{~h}$, after which LDL was added at a concentration of $20 \mu \mathrm{g} / \mathrm{ml}$. The cells were incubated for $24 \mathrm{~h}$ with the $\mathrm{LDL}$, and $0.5 \mu \mathrm{Ci}$ of $\left[{ }^{3} \mathrm{H}\right]$ thymidine was added for the last $4 \mathrm{~h}$. The radioactivity incorporated was estimated by scintillation spectrometry and expressed as the percentage of that in cells that were incubated in medium that lacked LDL. The LDL samples were isolated and oxidized LDL was prepared as described in Methods. Some samples included the antioxidant BHT during the oxidation reaction. To control for possible nonspecific effects, the samples labeled "no BHT," which indicates none during the oxidation reaction, had BHT added after that reaction, but before being placed on the smooth muscle cells for the growth assay. This is a single experiment that is representative of three, and the values shown represent the mean \pm SEM from triplicate incubations.

oxidation reaction. The growth-stimulating effect of oxidized LDL was apparent at concentrations as low as $2 \mu \mathrm{g} / \mathrm{ml}$ and increased up to $\sim 60 \mu \mathrm{g} / \mathrm{ml}$. At concentrations above $60 \mu \mathrm{g} /$ $\mathrm{ml}$, the oxidized LDL was toxic to the cells. The same toxic effect was observed at high concentrations of native LDL. Our results demonstrate that oxidized LDL stimulates the growth of smooth muscle cells. Further, they suggest that oxidation of LDL occurs during routine isolation and incubation.

In previous studies we showed that by exposing cells to strong oxidants, the membrane phospholipids were fragmented to generate compounds with the same physiological activities as PAF (39). The actions of these compounds on target cells were blocked by specific antagonists of the PAF receptor. PAF is known to have effects on smooth muscle cells including stimulation of growth and potentiation of the effect of PDGF (35). We considered the possibility that the growth-stimulating effects of oxidized LDL were accounted for by the generation of PAF-like oxidized phospholipids. We first tested whether PAF stimulated the incorporation of $\left[{ }^{3} \mathrm{H}\right]$ thymidine in bovine coronary artery smooth muscle cells and found a mitogenic effect that was maximal at $\sim 10 \mathrm{nM}$ and averaged $195 \pm 62 \%$ of control (five experiments). A representative experiment is shown in Fig. 2. However, we did not consistently find synergism with PDGF, which was a strong growth stimulus alone. This discrepancy with the results of Stoll and Spector (35) may reflect the differences in tissues and species used.

We next tested whether a synthetic, oxidized phospholipid, 1-palmitoyl-2-[5-oxovaleroyl]-sn-glycero-3-phosphocholine (5-AL-PC), could also stimulate smooth muscle cell growth. This compound, which is derived from oxidation of arachidonate in the precursor phospholipid, stimulates neutrophils

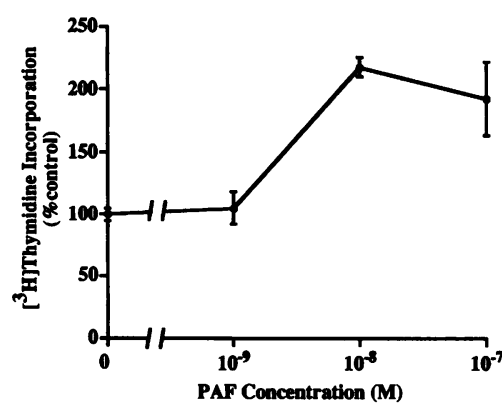

Figure 2. PAF simulates the growth of smooth muscle cells from bovine coronary arteries. Smooth muscle cells were cultured as described in Methods, and a growth assay was carried out as described in the legend of Fig. 1. In this experiment the cells were incubated in me

dium that contained BSA $(1 \mathrm{mg} / \mathrm{ml})$, or in the same medium with PAF for $20 \mathrm{~h}$ before the addition of $\left[{ }^{3} \mathrm{H}\right]$ thymidine. The results are expressed as a percentage of the values obtained in control incubations in which the cells were incubated in medium without serum. These results are from a single experiment that is representative of four additional experiments. The values represent the mean \pm SEM of triplicate determinations.

through the PAF receptor $(38,40)$. We found that 5-AL-PC stimulated the incorporation of $\left[{ }^{3} \mathrm{H}\right]$ thymidine in seven of eight experiments and that the maximal effect averaged $133 \pm 8 \%$ of control. The peak response occurred at concentrations between 1 and $10 \mathrm{nM}$. This stimulatory effect was abolished in experiments in which we blocked the receptor for PAF on the smooth muscle cells with WEB $2086(10 \mu \mathrm{M})$, a competitive antagonist (38) of the receptor $(n=2)$. As expected, this antagonist also blocked the response to PAF, but had no effect on the response to PDGF (positive control) or medium alone (negative control).

These results were consistent with the hypothesis that oxidized phospholipids structurally related to PAF could account for the growth-promoting action of oxidized LDL on smooth muscle cells. We examined this further by testing whether blockade of the PAF receptor would alter the proliferative response to oxidized LDL. We pretreated the cells with WEB $2086(10 \mu \mathrm{M})$ before exposing them to oxidized LDL, and included it during the coincubation. This completely blocked the growth-stimulating effect of oxidized LDL (Fig. 3). This suggested that oxidatively fragmented phospholipids in oxidized LDL are agonists for the growth of smooth muscle cells, and that they are generated during the oxidation process. Moreover, it indicated that all of the mitogenic activity was mediated through the PAF receptor on smooth muscle cells.

We next addressed the latter issue directly: were there PAFlike bioactive phospholipids in oxidized LDL? In our initial experiments, the effects of an unfractionated extract from oxidized LDL on PMN adhesion were not reproducible, activity was observed in some experiments but not all, and high concentrations of lipid were required. One possibility was that active phospholipids were present but not in solution or otherwise lacked access to the PAF receptor (e.g., they were sequestered in a micelle) due to the large amounts of cholesterol esters and triglycerides. Another possibility was that PAF-like oxidized phospholipids were generated, but had been hydrolyzed by the action of PAF acetylhydrolase. We addressed the first problem by isolating the phospholipids via aminopropyl column chromatography. The second problem was addressed by chemically inactivating the PAF acetylhydrolase in some of the LDL samples and then carrying out an oxidation reaction. We found (Fig. 4) that lipids extracted from LDL treated in this way consistently had activity that stimulated PMN adhesion $(n=5)$. In contrast, LDL in which the PAF acetylhydrolase had been 


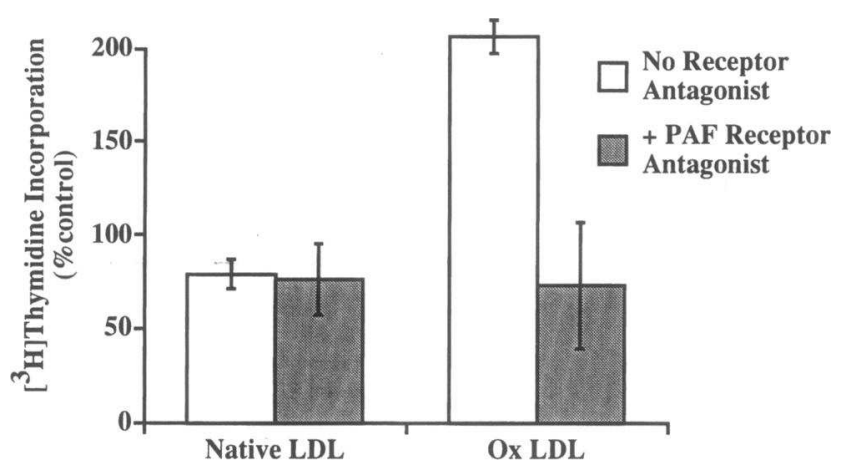

Figure 3. The growth-stimulating effect of oxidized LDL on arterial smooth muscle cells is blocked by an antagonist to the PAF receptor. Smooth muscle cells were cultured as described in Methods and a growth assay was carried out as described in the legend of Fig. 1. In this experiment, cells were incubated with LDL, either oxidized or native, at a concentration of $20 \mu \mathrm{g} / \mathrm{ml}$ for $24 \mathrm{~h} .0 .5 \mu \mathrm{Ci}$ of $\left[{ }^{3} \mathrm{H}\right]$ thymidine was added for the final $4 \mathrm{~h}$ of the incubation. The LDL samples were prepared and oxidized as described in Methods. The results are expressed as a percentage of the values obtained in control incubations in which the cells were incubated in medium without serum or lipoprotein. A PAF receptor antagonist, WEB $2086(10 \mu \mathrm{M})$, was added to the appropriate wells before the addition of the LDL. The receptor antagonist blocked the response to oxidized LDL but had no effect on the response to PDGF (not shown) or medium alone. This is a single experiment that is representative of two, and the values shown represent the mean \pm SEM from triplicate incubations.

inactivated, but which had not been oxidized, did not have PMN-activating lipids. The induction of PMN adhesiveness occurred at a total phospholipid concentration of $\sim 50 \mu \mathrm{M}$ and was equivalent in magnitude to the maximal PAF response. This value for the concentration of phospholipid required for optimal activity is a marked overestimate since it is based on total phospholipid, while the active compounds comprise only a small fraction of the total (see below). The response by PMNs was blocked by either of two antagonists of the PAF receptor,

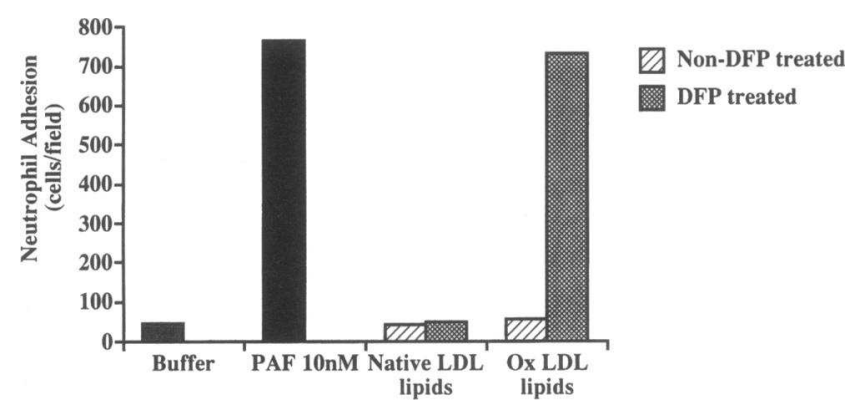

Figure 4. Lipids extracted from oxidized LDL stimulate neutrophil adhesion. LDL was isolated from human blood as described in Methods. One-half of the LDL sample was then incubated with diisopropylfluorophosphate (DFP) $5.7 \mathrm{mM}$ for $1 \mathrm{~h}$. One-half of both the DFP-treated and non-DFP-treated LDL samples were then oxidized by incubation with $10 \mu \mathrm{M}$ cupric sulfate. All fractions then underwent Bligh-Dyer extraction. The lower phase containing the lipids was separated, dried $\left(\mathrm{N}_{2}\right)$, and resuspended in HBSS with albumin for inclusion in the neutrophil adhesion assay for PAF-like bioactivity described in Methods. The results are expressed as number of neutrophils adherent to gelatin plates from a single experiment that is representative of five identical experiments.

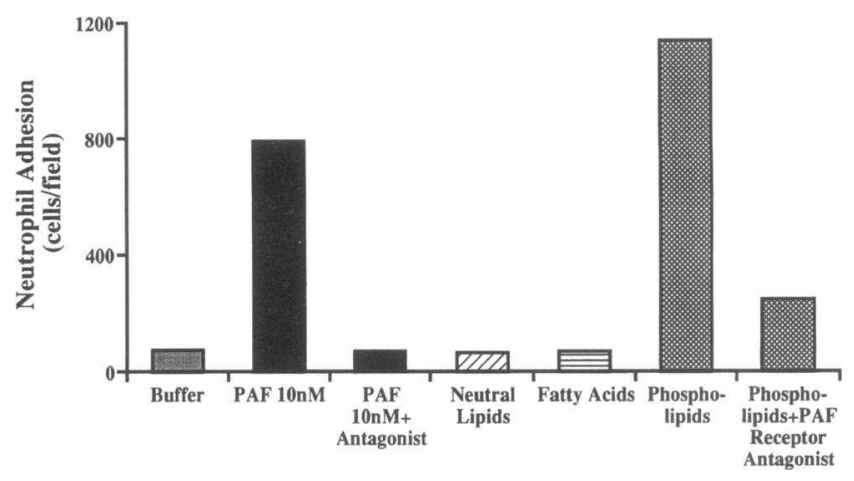

Figure 5. The bioactive lipids in oxidized LDL are in the phospholipid fraction. Initial purification of the bioactive compounds present in oxidized, LDL lipids was done by separation of total lipids into neutral lipids, fatty acids, and phospholipids by sequential elution over aminopropyl columns as described in Methods. Three lipid fractions were obtained and correspond to the classes listed above. The samples were dried $\left(\mathrm{N}_{2}\right)$ and resuspended in HBSS with albumin for inclusion in the neutrophil adhesion assay for PAF-like bioactivity described in Methods. A PAF receptor antagonist, L659,989 $(100 \mu \mathrm{M})$, was added to the appropriate wells before the addition of the agonist $P A F$ or phospholipids). The results are expressed as number of neutrophils adherent to gelatin-coated plates from a single experiment that is representative of five identical experiments.

WEB 2086 and L659,989. These compounds are unrelated chemically, which makes a nonspecific inhibitory effect unlikely. Further, they completely blocked the response of PMNs to PAF $\left(10^{-7} \mathrm{M}\right)$, but had no effect on their response to FMLP. Thus, oxidation of LDL under conditions that prevent the hydrolysis of PAF-like lipids results in the accumulation of such lipids that act via the PAF receptor.

We next turned to isolation and characterization of the bioactive lipid(s). We extracted the lipids from oxidized LDL, and separated the neutral lipids, fatty acids, and phospholipids. Bioactivity, measured as the ability to induce PMN adhesion, was entirely in the phospholipid fraction and was blocked by a PAF receptor antagonist (Fig. 5). This preparation of phospholipid was used for additional separation by reversed-phase HPLC. Fractions eluted from the HPLC column were dried, resuspended, and tested for bioactivity (Fig. 6). We found that the fractions that eluted at 6,7 (peak), and 8 min contained activity that induced PMN adhesion. Activation of PMNs by these HPLC fractions was again blocked with PAF receptor antagonists (data not shown). We also used this purification scheme to test for bioactivity in extracts of control LDL that had not been DFP-treated or oxidized, but found none (Fig. 6). In this HPLC system, lyso-phosphatidylcholine was eluted at 5 min, authentic PAF at $6 \mathrm{~min}$, and phosphatidylcholine at 21 min. Thus, the active compounds were significantly more polar than phosphatidylcholine, but less polar than lyso-phosphatidylcholine, which is an identical profile to what we and others have reported for oxidized phospholipids (39). The fact that PAF elutes at $6 \mathrm{~min}$ in this system indicates that the active compound is structurally similar to PAF. But there are compelling arguments, in addition to this physical separation, that it is not PAF. First, we assayed our LDL samples for PAF acetyltransferase, which is required for PAF synthesis, and found no activity. Second, we analyzed the fractions with bioactivity for PAF by mass spectrophotometry and found none (54). Thus, oxidized 


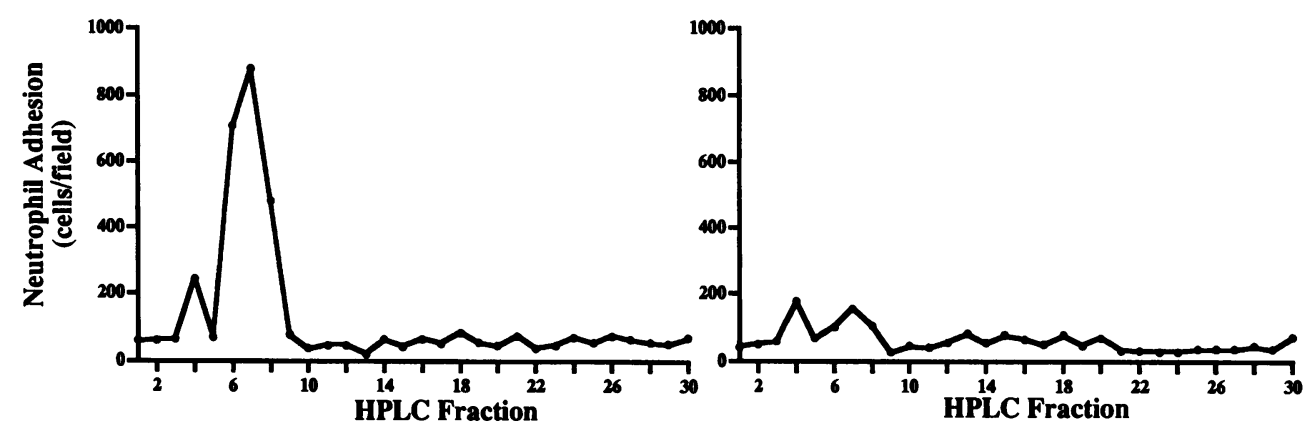

Figure 6. Separation by HPLC of stimulatory phospholipids extracted from oxidized LDL. Phospholipids extracted from oxidized LDL as described in the legends of Figs. 5 and 6 were dissolved in methanol/acetonitrile/water (840:150:10) containing $1 \mathrm{mM}$ ammonium acetate and injected on a $\mathrm{C} 18$ reversed-phase column which was then developed isocratically in this solvent. 1-ml fractions were collected every minute for $30 \mathrm{~min}$. The samples were dried $\left(\mathrm{N}_{2}\right)$ and then resuspended in HBSS with albumin for inclusion in the neutrophil adhesion assay as previously described. The results are expressed as number of neutrophils adherent to gelatin-coated plates from a single experiment that is representative of five. Neutrophil adhesion stimulated by the oxidized LDL lipids was blocked by incubation with a PAF receptor antagonist (data not shown).

LDL contains phospholipids that have undergone fragmentation of unsaturated fatty acids to yield compounds with pronounced autacoid activity.

The evidence at this point strongly supported the conclusion that the lipids extracted from oxidized LDL acted via the PAF receptor on target cells, but it was possible that other receptors were mediating the actions and that the inhibition by PAF receptor antagonists was nonspecific. To exclude this possibility, we assayed the effects of the fractions from the HPLC purification on CHO cells stably expressing the cloned human PAF receptor. The fractions (6-8) that had effects on PMNs also stimulated the release of arachidonate from the transfected cells, but not from the wild-type cells (Fig. 7). This effect was similar in magnitude to authentic PAF, and was blocked by the receptor antagonist. This result unequivocally demonstrated that the effect of these lipids was mediated via the receptor for PAF.

We then returned to the smooth muscle cell assay, this time using cells cultured from rat aorta, to determine if the HPLC fractions that had been active in the neutrophil and CHO cell assays would stimulate smooth muscle cell proliferation. HPLC fractions with PAF-like activity in the other assays also stimulated smooth muscle cell growth to $218 \pm 10 \%$ of control (four experiments with each conducted in triplicate). The same HPLC fractions from extracts of native LDL had no effect (Fig. 8). The mitogenic effect of the active fractions from oxidized LDL was blocked completely by the addition of a PAF receptor antagonist (two experiments using WEB 2086 at $10 \mu \mathrm{M}$ ). In an additional set of experiments we collected the active fractions from the first HPLC separation and further fractionated them on the same column but with a different mobile phase (system 2 in Methods). In two experiments we found that compound(s) that eluted at 19 min stimulated the growth of smooth muscle cells and activated PMNs, and that both actions were via the PAF receptor.

To further characterize the bioactive phospholipid, we treated the positive HPLC fractions with PAF acetylhydrolase, which is specific for short-chain residues at the $s n-2$ position of phosphoglycerides $(55,56)$. As shown in Fig. 9 , this treatment abolished the activity in HPLC fractions 6-8, while a shamincubation had no effect. Thus, the active oxidized phospholipids must have a short (or oxidized) acyl chain at the $s n-2$ position.

\section{Discussion}

Previous studies of the effects of LDL on vascular smooth muscle cell proliferation have reported variable results, although most workers have found stimulatory effects. Our experiments show that LDL protected with an antioxidant does not stimulate SMC proliferation, while oxidized LDL does. This suggests that some modification begins during the isolation procedure or perhaps is induced by the SMC themselves. The changes must be subtle as no differences were detected by changes in agarose mobility. As a technical point, this may explain the discrepancies in the previous studies. From a biological perspective, it indicates that the oxidation of LDL in vivo may generate compounds that stimulate the growth of smooth muscle cells. This
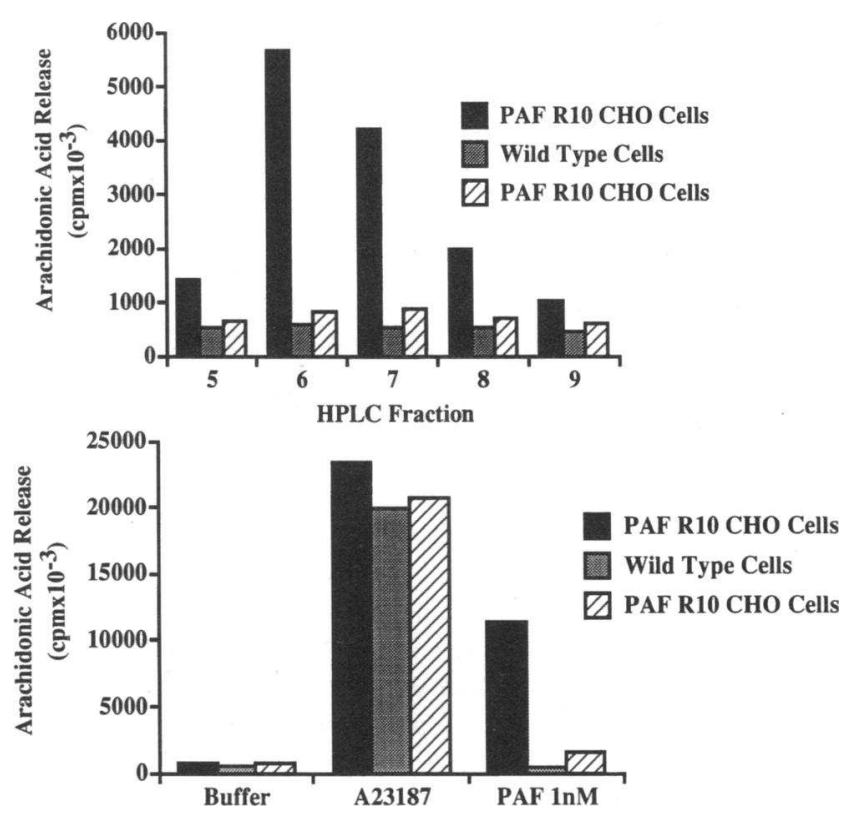

Figure 7. Phospholipids isolated from oxidized LDL stimulate the release of arachidonic acid from $\mathrm{CHO}$ cells stably transfected with a cDNA for the PAF receptor. Phospholipids isolated from oxidized LDL were incubated with $\mathrm{CHO}$ cells that had been stably transfected with the PAF receptor (PAF R1O CHO cells) and with wild-type CHO cells as described in Methods. The samples that were active in stimulating neutrophil adhesion also stimulated $\left[{ }^{3} \mathrm{H}\right]$ arachidonate release from the transfected $\mathrm{CHO}$ cells, but not from the wild-type $\mathrm{CHO}$ cells. This effect was blocked by the addition of a PAF receptor antagonist, WEB 2086 (striped bars). The transfected $\mathrm{CHO}$ cells and the wild type $\mathrm{CHO}$ cells both released $\left[{ }^{3} \mathrm{H}\right]$ arachidonate when treated with the calcium ionophore A23187, but not when treated with buffer alone. These results are from a single experiment that is representative of two identical experiments. 


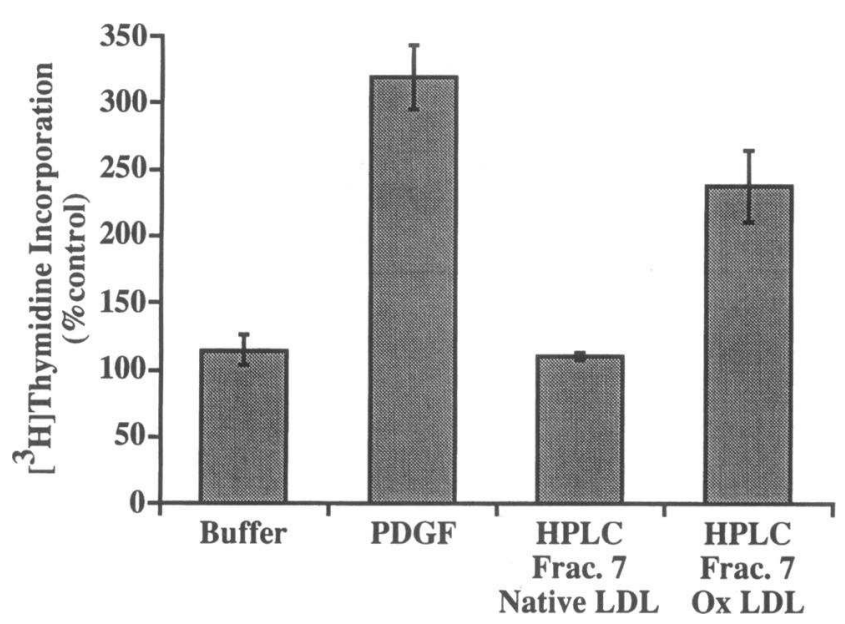

Figure 8. Phospholipids extracted from oxidized LDL stimulate smooth muscle cell growth. This effect is blocked by an antagonist to the PAF receptor. Rat aortic smooth muscle cells were cultured as described in Methods and were incubated with the indicated control and test compounds dissolved in PBS containing $0.1 \%$ BSA for $18 \mathrm{~h}$. The medium was supplemented with $1 \mu \mathrm{Ci}$ of $\left[{ }^{3} \mathrm{H}\right]$ thymidine for $1 \mathrm{~h}$. The radioactivity incorporated was then estimated by scintillation spectrometry and expressed as a percentage of the negative control. The cells were incubated with buffer alone, with PDGF ( $30 \mathrm{ng} / \mathrm{ml}$ ), with HPLC fraction 7 from oxidized LDL phospholipids and HPLC fraction 7 from negative (nonoxidized) LDL phospholipids. The results are from a single experiment that is representative of four. The values shown represent the mean \pm SEM of triplicate determinations.

could have important consequences in the pathogenesis of atherosclerosis since proliferation of these cells is a central feature of the disease, and because LDL is thought to be oxidatively modified at the site of atherosclerosis. The stimulatory effects of oxidized LDL, PAF, and 5-AL-PC were all blocked by an antagonist to the PAF receptor. Moreover, we directly demonstrated that a phospholipid(s) with physicochemical properties similar to PAF is generated by the oxidation of phospholipids in LDL and acts via the PAF receptor.

We identified a PAF-like compound in lipid-extracts of oxidized LDL by demonstrating that it stimulates neutrophil adhesion, activates CHO cells transfected with the PAF receptor, and stimulates SMC growth. Lysophosphatidylcholine has a variety of effects on smooth muscle cells $(31-33)$ so it was a candidate to explain our observations. However, in our experiments lysophosphatidylcholine was not active in the neutrophil and $\mathrm{CHO}$ cell assays. Also, the bioactive compound was inactivated by PAF acetylhydrolase, which hydrolyzes short acyl chains at the $s n-2$ position of phospholipids $(55,56)$ but has no effect on lysophosphatidylcholine. The stimulatory activity also was blocked with PAF receptor antagonists from two different chemical classes. Finally, we could exclude lysophosphatidylcholine as the active component since it was physically separated from the active fractions in our HPLC systems. From these results we conclude that oxidation of LDL produces compounds with both biologic and chemical similarities to PAF. This compound cannot be authentic PAF because the LDL particles do not contain the enzymatic apparatus for its synthesis, nor do they have acetyl coenzyme A. Instead, we conclude that it is a choline phosphoglyceride( $\mathrm{s}$ ) with a short-chain at the $s n-2$ position as a result of oxidative fragmentation. There may

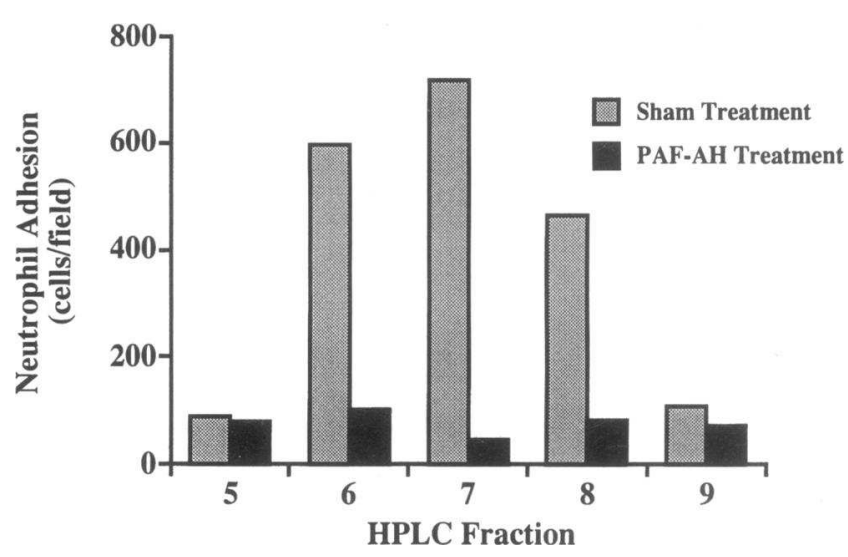

Figure 9. The bioactivity of phospholipids extracted from oxidized LDL is abolished by PAF acetylhydrolase. Phospholipids that had been isolated from oxidized LDL and shown to have PAF-like activity (Figs. $5-7)$ were incubated for $16 \mathrm{~h}$ with PAF acetylhydrolase (PAF-AH treatment) or with the same buffer (Sham treatment). After this incubation, the samples were tested for PAF-like bioactivity in the neutrophil adhesion assay as described in Methods. The results are expressed as number of neutrophils adherent to gelatin-coated plates from a single experiment that is representative of two identical experiments.

be an oxygen-containing substituent on this short chain. Benveniste and coworkers described the appearance of phospholipids with PAF-like activity when LDL was left exposed to air for long periods (57). They interpreted this as the release of "preformed" PAF from a cryptic site in the LDL particle. However, the active compound(s) had a retention time on HPLC that was clearly different from PAF and very similar to what we and others have shown for oxidized phospholipids. Thus, we suspect that the activity they described resulted from oxidative fragmentation of phospholipids in the LDL particles.

Although we were able to purify the active fractions extensively and show that they were phospholipids that had been oxidatively fragmented, we do not yet know their precise structure. Studies are in progress to determine the molecular structure of the active compounds from LDL. However, the chemistry of oxidized lipids is complicated and it is likely that there will be several compounds, as we observed even when a single synthetic phospholipid was used as the substrate (40). Further, it is likely that ratios of the oxidized products will change under different conditions. Tokomura et al. defined several oxidatively fragmented phospholipids isolated from a bovine brain lipid extract (58) and many of these were compounds that we described following the oxidation of 1-O-palmitoyl-2-arachidonoyl-sn-glycero-3-phosphocholine (40).

The inhibition of the PAF acetylhydrolase in LDL with DFP was an important technical point since it allowed the oxidized phospholipid to accumulate, which was essential for us to identify the biological activity. More importantly, this observation suggests that the PAF acetylhydrolase plays an important role in vivo, since removal of these compounds should mitigate the atherosclerotic process or other forms of vascular injury. Indeed, others have shown that HDL protects LDL from oxidation in vitro, a process which might explain some of its ability to lower the risk of vascular disease $(44,45)$. The recent findings that the slowing of LDL modification in vitro by HDL depends on active PAF acetylhydrolase $(46,47)$ are complementary to the results reported here. Aldehydes and other reactive compounds 
are formed from the polyunsaturated fatty acids at the $s n-2$ position of phospholipids during the oxidation of LDL, and these compounds can derivatize the apoprotein $(14,30)$. We conclude that the PAF acetylhydrolase protects by catalyzing the hydrolysis of such reactive groups, permitting them to diffuse away from the LDL particle or to be inactivated by some physiologic mechanism (i.e., reacting with albumin). This may be a key advantage resulting from the association of this enzyme with lipoproteins. However, this protective mechanism may be lost in strongly oxidizing environments since PAF acetylhydrolase is inactivated by oxidants $(46,59,60)$. Prevention of this inactivation may be an important effect of antioxidant therapy since it would preserve an enzymatic activity with antiinflammatory and antiatherogenic properties.

The present work also suggests a more direct role for oxidized phospholipids in vascular pathology. We found that oxidized LDL stimulates the proliferation of smooth muscle cells, that the effect is blocked by antagonists of the PAF receptor, and that PAF-like lipids are generated during the oxidation of LDL. We propose that oxidized phospholipids may be important in atherogenesis by virtue of their ability to stimulate the growth of smooth muscle cells. PAF receptors are expressed by many types of cells including smooth muscle, monocytes, macrophages, neutrophils, and platelets. Thus, the PAF-like oxidized phospholipids have multiple target cells and could play a role in both early atherogenesis, by stimulating smooth muscle cell growth, and in the clinical manifestations of atherosclerosis by initiating thrombosis. Our results further indicate that the PAF acetylhydrolase in lipoproteins may play a protective role by catalyzing the hydrolysis of these lipids.

\section{Acknowledgments}

We thank Drs. Kamala Patel and Fady Turquieh for helpful discussions, and Sue Cowley, Linda Wilcox, Margaret Vogel, Ruth Ann Green and Dr. Tada-atsu Imaizumi for valuable technical assistance. Dr. Patrick Gray (ICOS Corporation, Bothell, WA) generously provided the CHO cells transfected with the PAF receptor cDNA. We thank Drs. Kathleen Harrison and Robert Murphy (National Jewish Medical Center, Denver, $\mathrm{CO}$ ) for performing the mass spectrometry and Dr. Elizabeth Meade for performing the PAF acetyltransferase assay. Leona Montoya prepared the manuscript and Jason Burks designed the illustrations.

This work was supported in part by grants HL- 44513 and HL-50153 from the National Institutes of Health and funds from the Nora Eccles Treadwell Foundation. Drs. Heery and Kozak were supported during part of this work by Institutional Training Grant HL-07576 from the National Institutes of Health. Dr. Heery was also supported by an individual National Research Service Award HL08895-01, and Dr. Kozak was the recipient of an ACC/Merck Adult Cardiology Research Fellowship Award.

\section{References}

1. Castelli, W. P. 1984. Epidemiology of coronary heart disease: the Framingham study. Am. J. Med. 76:4-12.

2. Rose, G., and M. Shipley. 1986. Plasma cholesterol concentration and death from coronary heart disease: 10 year results of the Whitehall study. Br. Med. J. 293:306-307.

3. Stamler, J., D. Wentworth, and J. D. Neaton. 1986. Is relationship between serum cholesterol and risk of premature death from coronary heart disease continuous and graded? J. Am. Med. Assoc. 256:2823-2828.

4. Brown, M. S., and J. L. Goldstein. 1983. Lipoprotein metabolism in the macrophage: implications for cholesterol deposition in atherosclerosis. Annu. Rev. Biochem. 52:223-261.

5. Witztum, J., and D. Steinberg. 1991. Role of oxidized low density lipoprotein in atherogenesis. J. Clin. Invest. 88:1785-1792.
6. Steinberg, D., S. Parthasarathy, T. E. Carew, J. C. Khoo, and J. L. Witztum. 1989. Beyond cholesterol: Modifications of low-density lipoprotein that increase its atherogenicity. N. Engl. Med. 320:915-924.

7. Henriksen, T., E. M. Mahoney, and D. Steinberg. 1983. Enhanced macrophage degradation of biologically modified low density lipoprotein. Arteriosclerosis. 3:149-159.

8. Parthasarathy, S., D. J. Printz, D. Boyd, L. Joy, and D. Steinberg. 1986 Macrophage oxidation of low density lipoprotein generates a modified form recognized by the scavenger receptor. Arteriosclerosis. 6:505-510.

9. Sparrow, C. P., and J. Olszewski. 1992. Cellular oxidative modification of low density lipoprotein does not require lipoxygenases. Proc. Natl. Acad. Sci. USA. 89:128-131.

10. Bjorkhem, I., A. Henriksson-Freyschuss, O. Breuer, U. Diczfalusy, L. Berglund, and P. Henriksson. 1991. The antioxidant butylated hydroxytoluene protects against atherosclerosis. Arterioscler. Thromb. 11:15-22.

11. Sparrow, C. P., T. W. Doebber, J. Olszewski, M. S. Wu, J. Ventre, K. A Stevens, and Y.-S. Chao. 1992. Low density lipoprotein is protected from oxidation and the progression of atherosclerosis is slowed in cholesterol-fed rabbits by the antioxidant $N, N^{\prime}$-diphenyl-phenylenediamine. J. Clin. Invest. 89:1885-1891.

12. Mao, S. J. T., M. T. Yates, R. A. Parker, E. M. Chi, and R. L. Jackson 1991. Attenuation of atherosclerosis in a modified strain of hypercholesterolemic Watanabe rabbits with use of a probucol analogue (MDL 29,311) that does not lower serum cholesterol. Arterioscler. Thromb. 11:1266-1275.

13. Carew, T. E., D. C. Schwenke, and D. Steinberg. 1987. Antiatherogenic effect of probucol unrelated to hypocholesterolemic effect: evidence that antioxidants in vivo can selectively inhibit low density lipoprotein degradation in macrophage-rich fatty streaks and slow progression of atherosclerosis in the Watanabe heritable hyperlipidemic rabbit. Proc. Natl. Acad. Sci. USA. 84:7725-7729.

14. Steinbrecher, U. P., M. Lougheed, W.-C. Kwan, and M. Dirks. 1989 Recognition of oxidized low density lipoprotein by the scavenger receptor of macrophages results from derivatization of apolipoprotein B by products of fatty acid peroxidation. J. Biol. Chem. 264:15216-15223.

15. Goldstein, J. L., Y. K. Ho, S. K. Basu, and M. S. Brown. 1979. Binding site on macrophages that mediates uptake and degradation of acetylated low density lipoprotein, producing massive cholesterol deposition. Proc. Natl. Acad. Sci. USA. 76:333-337.

16. Stein, O., and Y. Stein. 1980. Bovine aortic endothelial cells display macrophage-like properties toward acetylated ${ }^{125}$ I-labelled low density lipoprotein. Biochim. Biophys. Acta. 620:631-635.

17. Cushing, S. D., J. A. Berliner, A. J. Valente, M. C. Territo, M. Navab, F. Parhami, R. Gerrity, C. J. Schwartz, and A. M. Fogelman. 1990. Minimally modified low density lipoprotein induces monocyte chemotactic protein 1 in human endothelial cells and smooth muscle cells. Proc. Natl. Acad. Sci. USA. 87:5134-5138.

18. Rajavashisth, T. B., A. Andalibi, M. C. Territo, J. A. Berliner, M. Navab, A. M. Fogelman, and A. J. Lusis. 1990. Induction of endothelial cell expression of granulocyte and macrophage colony-stimulating factors by modified low-density lipoproteins. Nature (Lond.). 344:254-257.

19. Kugiyama, K., S. A. Kerns, J. D. Morrisett, R. Roberts, and P. Henry. 1990. Impairment of endothelial-dependent arterial relaxation by lysolecithin in modified low-density lipoproteins. Nature (Lond.). 344:160-162.

20. Yokoyama, M., K.-I. Hirata, R. Miyake, H. Akita, Y. Ishikawa, and H. Fukuzaki. 1990. Lysophosphatidylcholine: essential role in the inhibition of endothelium-dependent vasorelaxation by oxidized low density lipoprotein. Biochem. Biophys. Res. Commun. 168:301-308.

21. Galle, J., E. Bassenge, and R. Busse. 1990. Oxidized low density lipoproteins potentiate vasoconstriction to various agonists by direct interaction with vascular smooth muscle. Circ. Res. 66:1287-1293.

22. Fless, G. M., R. Kirchhausen, K. Fischer-Dzoga, R. W. Wissler, and A. M. Scanu. 1982. Serum low density lipoproteins with mitogenic effect on cultured aortic smooth muscle cells. Atherosclerosis. 41:171-183.

23. Koschinsky, T., C. E. Bunting, R. Rutter, and F. A. Gries. 1987. Increased growth stimulation of human vascular cells by serum from patients with primary hyper-LDL-cholesterolemia. Atherosclerosis. 63:7-13.

24. Block, L. H. M. Knorr, E. Vogt, R. Locher, W. Vetter, P. Groscurth, B.-Y. Qiao, D. Pometta, R. James, M. Regenass, and A. Pletscher. 1988. Low density lipoprotein causes general cellular activation with increased phosphatidylinositol turnover and lipoprotein catabolism. Proc. Natl. Acad. Sci. USA. 85:885 889.

25. Scott-Burden, T., T. J. Resink, A. W. A. Hahn, U. Baur, R. J. Box, and F. R. Buhler. 1989. Induction of growth-related metabolism in human vascular smooth muscle cells by low density lipoprotein. J. Biol. Chem. 264:12582-12589.

26. Sachinidis, A., R. Locher, A. Steiner, T. Mengden, and W. Vetter. 1989. Effect of low-density lipoprotein on intracellular calcium, intracellular $\mathrm{pH}$ and DNA synthesis in cultured vascular smooth muscle cells. J. Hyperten. 7:116117.

27. Sachinidis, A., T. Mengden, R. Locher, C. Brunner, and W. Vetter. 1990 Novel cellular activities for low density lipoprotein in vascular smooth muscle cells. Hypertension (Dallas). 15:704-711.

28. Weisser, B., R. Locher, T. Mengden, and W. Vetter. 1992. Oxidation of 
low density lipoprotein enhances its potential to increase intracellular free calcium concentration in vascular smooth muscle cells. Arterioscler. Thromb. 12:231 236.

29. Resink, T. J., V. A. Tkachuk, J. Bernhardt, and F. R. Buhler. 1992 Oxidized low density lipoproteins stimulate phosphoinositide turnover in cultured vascular smooth muscle cells. Arterioscler. Thromb. 12:278-285.

30. Esterbauer, H., G. Jurgens, O. Quehenberger, and E. Koller. 1987. Autoxidation of human low density lipoprotein: loss of polyunsaturated fatty acids and vitamin E and generation of aldehydes. J. Lipid Res. 28:495-509.

31. Quinn, M. T., S. Parthasarathy, and D. Steinberg. 1988. Lysophosphatidylcholine: a chemotactic factor for human monocytes and its potential role in atherogenesis. Proc. Natl. Acad. Sci. USA. 85:2805-2809.

32. Zwijsen, R. M. L., S. C. Japenga, A. M. P. Heijen, R. C. van den Bos, and J. H. Koeman. 1992. Induction of platelet-derived growth factor chain a gene expression in human smooth muscle cells by oxidized low density lipoproteins. Biochem. Biophys. Res. Commun. 186:1410-1416.

33. Locher, R., B. Weisser, T. Mengden, C. Brunner, and W. Vetter. 1992. Lysolecithin actions on vascular smooth muscle cells. Biochem. Biophys. Res. Commun. 183:156-162.

34. Venable, M. E., G. A. Zimmerman, T. M. McIntyre, and S. M. Prescott. 1993. Platelet-activating factor: a phospholipid autacoid with diverse actions. $J$. Lipid Res. 34:691-702.

35. Stoll, L. L., and A. A. Spector. 1989. Interaction of platelet-activating factor with endothelial and vascular smooth muscle cells in coculture. J. Cell Physiol. 139:253-261.

36. Honda, Z. I., M. Nakamura, I. Miki, M. Minami, T. Watanabe, Y. Seyama, H. Okado, H. Toh, K. Ito, T. Miyamoto, and T. Shimizu. 1991. Cloning by functional expression of platelet-activating factor receptor from guinea-pig lung. Nature (Lond.). 349:342-346.

37. Nakamura, M., Z.-I. Honda, T. Izumi, C. Sakanaka, H. Mutoh, M. Minami H. Bito, Y. Seyama, T. Matsumoto, M. Noma, and T. Shimizu. 1991. Molecular cloning and expression of platelet-activating factor receptor from human leukocytes. J. Biol. Chem. 266:20400-20405.

38. Smiley, P. L., K. E. Stremler, S. M. Prescott, G. A. Zimmerman, and T. M. McInytre. 1991. Oxidatively fragmented phosphatidylcholines activate human neutrophils through the receptor for platelet-activating factor. J. Biol. Chem. 266:11104-11110.

39. Patel, K. D., G. A. Zimmerman, S. M. Prescott, and T. M. McIntyre. 1992. Novel leukocyte agonists are released by endothelial cells exposed to peroxide. $J$. Biol. Chem. 267:15168-15175.

40. Stremler, K. E., D. M. Stafforini, S. M. Prescott, G. A. Zimmerman, and T. M. McIntyre. 1989. An oxidized derivative of phosphatidylcholine is a substrate for the platelet-activating factor acetylhydrolase from human plasma. J. Biol. Chem. 264:5331-5334.

41. Stremler, K. E., D. M. Stafforini, S. M. Prescott, and T. M. McIntyre 1991. Human plasma PAF acetylhydrolase: oxidatively-fragmented phospholipids as substrates. J. Biol. Chem. 266:11095-11103.

42. Stafforini, D. M., S. M. Prescott, and T. M. McIntyre. 1987. Human plasma platelet-activating factor acetylhydrolase: purification and properties. $J$. Biol. Chem. 262:4223-4230.

43. Stafforini, D. M., T. M. McIntyre, M. E. Carter, and S. M. Prescott. 1987. Human plasma platelet-activating factor acetylhydrolase: association with lipoprotein particles and role in the degradation of platelet-activating factor. $J$. Biol. Chem. 262:4215-4222.

44. Klimov, A. N., A. A. Nikiforova, V. M. Pleskov, A. A. Kuzmin, N. N.
Kalashnikova, and T. O. Antipova. 1989. The protective effect of high density lipoproteins, their subfractions and lecithin: cholesterol acyltransferase on the peroxidative modification of low density lipoproteins. Biochimiya. 54:118-123.

45. Parthasarathy, S., J. Barnett, and L. G. Fong. 1990. High-density lipoprotein inhibits the oxidative modification of low-density lipoprotein. Biochim. Biophys. Acta. 1044:275-283.

46. Stafforini, D. M., G. A. Zimmerman, T. M. McIntyre, and S. M. Prescott. 1992. The platelet-activating factor acetylhydrolase from human plasma prevents oxidative modification of low-density lipoprotein. Trans. Assoc. Am. Phys. 105:44-63.

47. Watson, A. D., M. Navab, S. Y. Hama, A. Sevanian, S. M. Prescott, D. M. Stafforini, T. M. McIntyre, B. N. La Du, A. M. Fogelman, and J. A. Berliner. 1995. Effect of platelet activating factor-acetylhydrolase on the formation and action of minimally oxidized low density lipoprotein. J. Clin. Invest. 95:774782

48. Chung, B. H., T. Wilkinson, J. C. Geer, and J. P. Segrest. 1980. Preparative and quantitative isolation of plasma lipoproteins: rapid, single discontinuous density gradient ultracentrifugation in a vertical rotor. J. Lipid Res. 21:284-291.

49. Bligh, E. G., and W. J. Dyer. 1959. A rapid method of total lipid extraction and purification. Can. J. Biochem. Physiol. 37:911-917.

50. Ames, B. N., and D. T. Dubin. 1960. The role of polyamines in the neutralization of bacteriophage deoxyribonucleic acid. J. Biol. Chem. 235:769775

51. Kaluzny, M. A., L. A. Duncan, M. V. Merritt, and D. E. Epps. 1985. Rapid separation of lipid classes in high yield and purity using bonded phase columns. J. Lipid Res. 26:135-140.

52. Zimmerman, G. A., T. M. McIntyre, M. Mehra, and S. M. Prescott. 1990. Endothelial cell associated platelet-activating factor: a novel mechanism for signaling intercellular adhesion. J. Cell Biol. 110:529-540.

53. Zimmerman, G. A., T. M. McIntyre, and S. M. Prescott. 1985. Thrombin stimulates the adherence of neutrophils to human endothelial cells in vitro. $J$. Clin. Invest. 76:2235-2246.

54. Clay, K. L. 1990. Quantitation of platelet-activating factor by gas chromatography-mass spectrometry. In Methods in Enzymology: Arachidonate Related Lipid Mediators Volume 187. R.C. Murphy and F.A. Fitzpatrick, editors. Academic Press, Inc., San Diego, CA. 134-142.

55. Stremler, K. E., D. M. Stafforini, S. M. Prescott, and T. M. McInytre. 1991. Human plasma platelet-activating factor acetylhydrolase: oxidatively-fragmented phospholipids as substrates. J. Biol. Chem. 266:11095-11103.

56. Tjoelker, L. W., C. Wilder, C. Eberhardt, D. M. Stafforini, G. Dietsch, B. Schimpf, S. Hooper, H. L. Trong, L. S. Cousens, G. A. Zimmerman, et al. 1995. Anti-inflammatory properties of a platelet-activating factor acetylhydrolase. Nature (Lond.) 374:549-553.

57. Benveniste, J., D. Nunez, P. Duriez, R. Korth, J. Bidault, and J. C. Fruchart. 1988. Preformed PAF-acether and lyso PAF-acether are bound to blood lipoproteins. FEBS Lett. 226:371-376.

58. Tanaka, T., H. Minamino, S. Unezaki, H. Tsukatani, and A. Tokumura. 1993. Formation of platelet-activating factor-like phospholipids by $\mathrm{Fe} 2+$ /ascorbate/EDTA-induced lipid peroxidation. Biochim. Biophys. Acta. 1166:264-274.

59. Dentan, C., P. Lesnik, M. J. Chapman, and E. Ninio. 1994. PAF-acetherdegrading acetylhydrolase in plasma LDL is inactivated by copper-and cell-mediated oxidation. Arterioscler. Thromb. 14:353-360.

60. Ambrosio, G., A. Oriente, C. Napoli, G. Palumbo, P. Chiariello, G. Marone, M. Condorelli, M. Chiariello, and M. Triggiani. 1994. Oxygen radicals inhibit human plasma acetylhydrolase, the enzyme that catabolizes platelet-activating factor. J. Clin. Invest. 93:2408-2416. 